\title{
A mulher moderna como fotógrafa na guerra: Margaret Michaelis e Kati Horna*
}

Erika Zerwes**

\section{Resumo}

Para discutir alguns dos aspectos da questão de gênero na história da fotografia, bem como fazer uma análise das possíveis relações entre essa atuação feminina e a cultura política do período, este artigo fala sobre o trabalho de Kati Horna e Margaret Michaelis na Espanha. Elas nasceram mulheres e judias, e se fizeram fotógrafas e anarquistas durante a década de 1930. Fazem parte de uma geração de mulheres que encontraram na fotografia uma possibilidade de, ao mesmo tempo, ter independência financeira, fazer um trabalho criativo $e$ artístico, e ter uma atuação política efetiva.

Palavras-chave: Margaret Michaelis, Kati Horna, Anarcofeminismo, Fotografia e Gênero, Cultura Visual.

" Recebido em 22 de maio de 2016, aceito em 27 de julho de 2017. Este artigo é um dos resultados da pesquisa "As noções de humanismo na fotografia documental entre as décadas de 1930 e 1960" financiada pela Fapesp."

** Pós Doutoranda no Museu de Arte Contemporânea da Universidade de São Paulo, MAC-USP, São Paulo, Brasil. Bolsista FAPESP. erikazerwes@gmail.com 


\title{
The Modern Woman as War Photographer: Margaret Michaelis and Kati Horna
}

\begin{abstract}
Focusing on Kati Horna's and Margaret Michaelis' photographs made in Spain, this paper intends to discuss some aspects of the gender issue in history of photography, as well as analyse some of the possible relations between the feminine participation and the political culture of that moment. They were born women and Jewish, and made themselves photographers and anarchists during the 1930s. They are part of a generation of women who found in photography a possibility of, at the same time, be financially independent, have an artistic and creative work, and take political action.
\end{abstract}

Keywords: $\quad$ Margaret Michaelis; Kati Horna; Anarcho-feminism; Photography \& Gender; Visual Culture. 


\section{Biografias}

Margaret Michaelis nasceu Margarethe Gross, em 1902, na cidade de Dzieditz, que naquele momento pertencia à Áustria, mas devido aos acontecimentos da Primeira Guerra Mundial passou, depois de 1919, a pertencer à Polônia. Ela realizou em Viena, entre 1918 e 1921, uma formação técnica em fotografia bastante completa, e em seguida, trabalhou em estúdios fotográficos em Viena, Praga e Berlim. Foi em Berlim que, em 1929, ela conheceu seu primeiro marido, o militante do grupo anarco-sindicalista FAUD (Freie Arbeiter Union Deutschlands, ou União dos Trabalhadores Livres da Alemanha), Rudolf Michaelis. Em 30 de janeiro de 1933, Hitler assumiu o poder na Alemanha e suprimiu a FAUD, e, nos meses seguintes, primeiro Margaret, e depois seu marido, foram presos. Em dezembro desse mesmo ano, temendo por sua segurança, o casal deixou a Alemanha em direção à Espanha, para onde já haviam imigrado amigos alemães também membros da FAUD. Nesse país, Michaelis abriu um estúdio fotográfico onde fazia retratos, mas também fotografia publicitária, além de trabalhar em proximidade com os arquitetos de esquerda do GATCPAC, um braço catalão do CIAM (Congrès Internationa dArchitecture Moderne) e muito ligado ao governo republicano. Margaret e Rudolf já estavam separados quando a sublevação militar comandada pelo General Franco iniciou o conflito civil, em julho de 1936. Em outubro de 1937, Rudolf foi preso durante os expurgos stalinistas contra os trotskistas, e contra parte dos sindicatos e movimentos anarquistas (ver Orwell, 2006:146-222), que pode ter contado para a decisão de Margaret de deixar a Espanha ao final do mesmo ano. As dificuldades levantadas pelo anti-semitismo na Europa continental a levaram a buscar um visto para a Inglaterra, e depois para fora do continente. Em julho de 1939, o pedido que ela havia feito de visto para a Austrália foi concedido, e ela foi para Sydney, onde abriu um estúdio de retratos fotográficos em 1940. Durante os anos da Segunda Guerra Mundial, ela permaneceu sob vigilância do governo por ser um "inimigo estrangeiro". Ao fim da guerra, se naturalizou australiana 
e, em 1960 se casou pela segunda vez, com o também imigrante austríaco, Albert George Sachs. Ela faleceu em Melbourne, em 1986 (Ennis, 2005; Mendelson, Lahuerta, 1998).

Assim como Michaelis, Horna era também de família judia. Nasceu Katalin Deutsch Blau, em 1912, na cidade de Szilasbalhás, na Hungria - então parte do Império Austro-Húngaro. Mudou-se muito cedo com a família para Budapeste, onde mais tarde tomou contato com o grupo Munka, dirigido por Lajos Kassák, que unia artistas e intelectuais de esquerda. Ainda jovem saiu de casa para completar seus estudos e, em 1930 - um ano depois de Michaelis Horna foi para Berlim, onde transitou pelo círculo de Bertold Brecht e da Bauhaus. Com a escalada do nazismo e do antisemitismo, ela voltou para Budapeste em 1933, onde fez um curso intensivo de fotografia no estúdio do fotógrafo, inventor $e$ educador húngaro József Pécsi (1889-1956), por onde também passaram, quando jovens, os futuros fotógrafos Robert Capa e Eva Besnyö, entre outros. No mesmo ano de 1933, Horna se mudou para Paris, onde morou até 1937. Lá, iniciou um trabalho fotográfico associado ao mesmo tempo às vanguardas e à reportagem fotográfica. Sua viagem para a Espanha para fotografar o conflito iniciado no ano anterior interrompeu esse trabalho. Chegou àquele país por meio do Comitê de Propaganda Exterior da CNT, a Confederação Nacional do Trabalho, organização anarco-sindicalista ligada à Associação Internacional dos Trabalhadores, e que participava do governo de Frente Popular espanhol. Todo o tempo em que lá esteve, Horna trabalhou para a imprensa anarquista, especialmente para as revistas Umbral, Mujeres Libres e Tierra y Libertad. Quando ela fugiu para a França, ao final da guerra civil, carregou consigo uma lata contendo seus negativos e fotomontagens. Essa mesma lata seguiu com ela no navio até o México, e nela estavam suas únicas imagens que sobreviveram àquela época (Moorhead, 2010:54-68; Rodriguez et al, 2013:17-105).

É possível, portanto, identificar significativos pontos em comum nas biografias de Margaret Michaelis e Kati Horna. Suas vidas foram se desenvolvendo de forma paralela e, em certa 
medida, podem ser vistas como exemplares de tantas histórias de vida de homens e mulheres em tempos sombrios. Elas viveram muito jovens e em primeira mão os sofrimentos da Europa durante Primeira Guerra Mundial, e se formaram durante o tumultuado período que se seguiu. Ambas eram de família judia de classe média, com ideais políticos de esquerda. Ambas estiveram na Alemanha durante os momentos finais da República de Weimar, e o início da subida ao poder do nacional-socialismo. $\mathrm{Na}$ segunda metade da década de 1930, incentivadas pelas perseguições políticas aos membros das esquerdas, bem como pelo anti-semitismo, ambas estiveram na Espanha e lá colocaram seu ofício de fotógrafas à serviço da luta contra o fascismo. Perdida essa luta, nenhuma das duas permaneceu na Europa como se viu, Michaelis imigrou para a Austrália e Horna foi como refugiada para o México.

Por muitos anos, o trabalho delas como fotógrafas da Guerra Civil Espanhola (1936-1939) permaneceu desconhecido do público em geral. Ambas parecem ter tentado reconstruir suas vidas nos países para os quais imigraram deixando o passado de lado. Apenas depois de muitas décadas, com o fim da ditadura após a morte de Franco - em 1975, e depois que as fotógrafas já estavam com a idade bastante avançada, suas atuações como fotógrafas de guerra foram trazidas novamente à público.

O arquivo espanhol de Horna é constituído por 270 fotografias $e$ fotomontagens. As imagens foram doadas por ela para o Archivo Histórico Nacional espanhol (hoje Archivo General de la Guerra Civil Española, localizado em Salamanca) em 1983. $\mathrm{O}$ arquivo de Michaelis está localizado na National Gallery of Autralia, em Canberra, e foi doado pela fotógrafa poucas semanas antes de sua morte, em 1986. A coleção completa incorporada ao museu consiste em cerca de 450 imagens e uma caixa contendo cartas e papéis pessoais. Desse total, cerca de 125 imagens foram feitas na Espanha durante o conflito.

Os dois arquivos fotográficos, por tanto tempo desconhecidos, nos permitem hoje refletir sobre alguns aspectos específicos do momento histórico em que essas mulheres viveram. 
Como resultado de uma primeira aproximação da pesquisa histórica nos dois arquivos, propomos discutir dois aspectos centrais que emergem quando os defrontamos - o da presença feminina na profissão de fotógrafas, e o da militância anarquista durante o conflito na Espanha.

\section{A nova mulher}

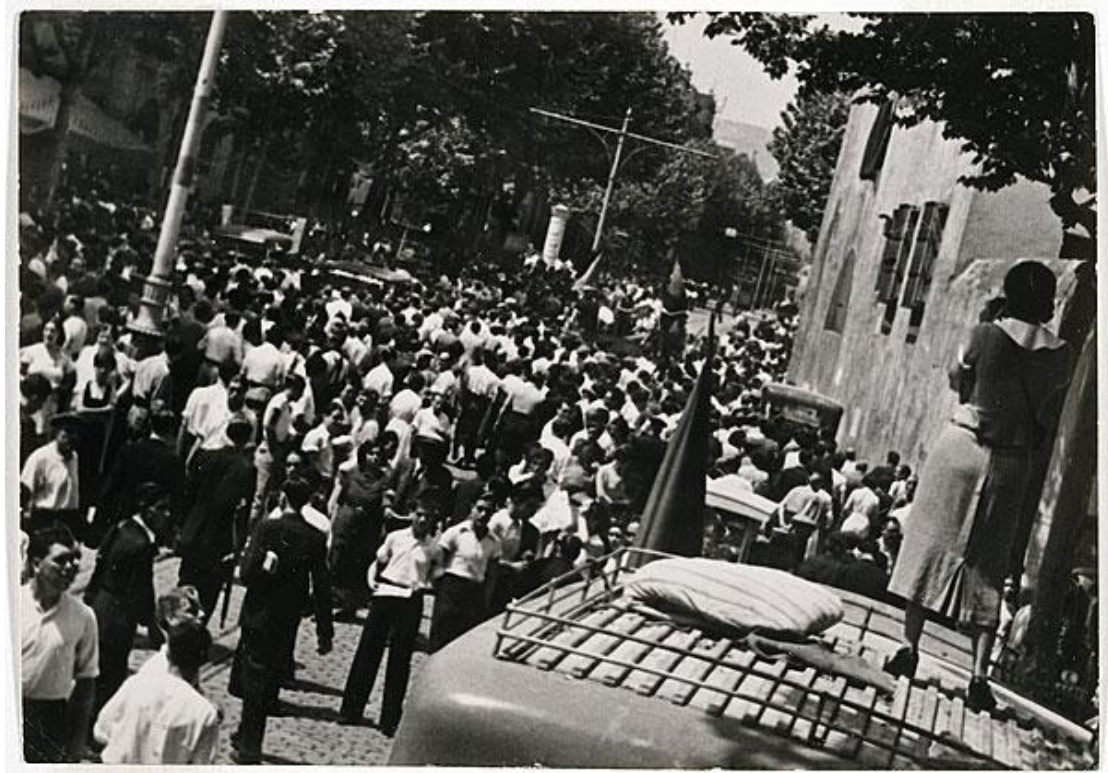

Imagem 1 - Margaret Michaelis. O funeral de Durruti, Barcelona, 1936. Fonte: National Gallery of Australia [http://cs.nga.gov.au/Detail.cfm?IRN=48694].

Entre as fotografias mais antigas que sobreviveram no arquivo de Michaelis, estão alguns retratos femininos feitos por volta de 1924, em que a modelo aparece com pose um pouco altiva, vestimenta moderna e corte curto de cabelo. A biógrafa de Michaelis, Helen Ennis (2005:24), em Margaret Michaelis: Love, loss and photography, notou que essas características eram 
próprias de uma geração de mulheres que passou a ser chamada de neue Frau, a nova mulher.

As denominações de neue Frau em alemão, new woman em inglês, garçonne em francês, ou ainda a flapper, trampky, a sufragista, a mulher moderna, entre outras, podem ser vistas como manifestações diversas de um fenômeno semelhante, que acompanhou a maior visibilidade da mulher no espaço público, ocorrida principalmente nas primeiras décadas do século XX. Elizabeth Otto e Vanessa Rocco descrevem essa pluralidade de formas pelas quais o fenômeno da mulher moderna se manifestou no livro The new woman international. Segundo as autoras,

É tão difícil definir o que queremos dizer com a "Nova Mulher", quanto é fácil encontrar exemplos de sua imagem onipresente, não só na Europa Ocidental, mas em todo o mundo na era que se estende desde o fin de siècle até a década de 1930, e mesmo até as décadas seguintes. A Nova Mulher é, por excelência, definida pelas fotografias e filmes da Alemanha de Weimar em figuras como Lulu, de Louise Brooks, no filme de G. W. Pabst Pandora's Box (1929): sedutora, autoconfiante, sexualmente ambígua? Ou ela é mais concretamente incorporada no valente ativismo $e$ experiência profissional da aviadora americana Amelia Earhart? É a Nova Mulher - imaginada como vampira ou sedutora - apenas um avatar atualizado de um topos feminino tradicional: uma versão simplificada de Delilah; Salome; ou, mais recentemente, Becky Sharp ou Mata Hari? Ou ela é uma firme lutadora pela igualdade de direitos, pelo sufrágio e pelo trabalho significativo para as mulheres, uma batalhadora pela a independência feminina $e$ a autodeterminação, incorporada de forma mais pungente em fotos $e$ cartazes de mulheres republicanas envolvidas na Guerra Civil Espanhola? Certamente, essas duas visões não são idênticas; de fato, são contraditórias, embora existam muitas imagens - como o autorretrato de Tamara de Lempicka em um Bugatti verde de 1925, mostrando a artista elegante ao volante do seu carro de alta potência - que tentam unir o sexy com a autopropulsão. 
No entanto, o que todas as Novas Imagens da Nova Mulher têm em comum, flapper ou vamp, revolucionária política ou suffragette, é uma rejeição sincera do papel tradicional da mulher como foi definido por todas as sociedades do mundo: a rebelião contra as noções opressivas do "feminino", entendida como uma vida dedicada a subordinar as próprias necessidades e desejos aos homens, familiares e filhos (Otto; Rocco, 2011:vi). ${ }^{1}$

Essa multifacetada construção histórica da figura e do papel da mulher entre o final do século XIX e a primeira metade do XX perpassou os mais variados momentos históricos, tais como o colonialismo, o modernismo, revoluções políticas $e$ as duas guerras mundiais; perpassou também os mais variados cenários urbanos da Europa, das Américas e Ásia. ${ }^{2}$ Da mesma forma, e não

1 As traduções são livres, feitas pela autora. No original: "It is as hard to define what we mean by the "New Woman" as it is easy to find examples of her ubiquitous image not only in Western Europe but throughout the world in the era extending from the fin-de-siècle to the 1930s, and even to the decades beyond. Is the New Woman quintessentially defined by the photography and film of Weimar Germany in such figures as Louise Brooks's Lulu in G. W. Pabst's film Pandora's Box (1929): seductive, self-aggrandizing, sexually ambiguous? Or is she more truly embodied in the courageous activism and professional expertise of the American aviator Amelia Earhart? Is the New Woman - envisioned as vamp or seductress - merely an updated avatar of a time-honored female topos: a streamlined version of Delilah; Salome; or, more recently, Becky Sharp or Mata Hari? Or is she a stalwart fighter for equal rights, the suffrage, and meaningful work for women, a battler for female independence and self-determination most poignantly embodied in photos and posters of Republican women engaged in the Spanish Civil War? Certainly, these two visions are not identical; indeed, they are contradictory, although there are many images, like Tamara de Lempicka's Self Portrait in a Green Bugatti of 1925, showing the elegant artist at the wheel of her high-powered car, that attempt to weld the sexy with the self-propelling. Yet what all New Images of the New Woman do have in common, flapper or vamp, political revolutionary or suffragette, is a heartfelt rejection of woman's traditional role as it was defined by every society in the world: rebellion against oppressive notions of the "womanly" understood to be a life devoted to subordinating one's own needs and desires to those of men, family, and children".

2 Existe um grupo internacional dedicado a estudar os variados aspectos $e$ aparições da chamada mulher moderna. Os autores de um estudo com as 
por acaso, esse desenvolvimento da noção de mulher moderna foi apoiado pelo, ao mesmo tempo se beneficiou do,apoiou, no contemporâneo desenvolvimento da comunicação de massas.

Segundo Ute Eskildsen (1995:63), a fotografia e a imprensa ilustrada tiveram um papel fundamental nessa construção. A autora ressalta que, a partir dos anos de 1920, na Alemanha, a mulher se tornou um assunto privilegiado para a imprensa. Assim como passou a ser mais e mais representada nas páginas de jornais e revistas - aparecendo ao mesmo tempo como uma mercadoria, comercializada pela imprensa, e como uma parte grande do público alvo das reportagens e anúncios publicitários ela também passou a estar presente entre os profissionais de imprensa, inclusive como fotógrafa.

A Alemanha de Weimar, e em especial Berlim, parece ter sido um palco importante da formação da chamada mulher moderna. A capital alemã foi uma das primeiras cidades a ser nomeada de metrópole, e já nos anos 1920 era um dos mais importantes centros onde se desenvolveram discursos da modernidade em diversos de seus aspectos, especialmente no que dizia respeito à tecnologia e ao progresso, mas também nos âmbitos cultural e de costumes. Ao mesmo tempo que Berlim era vista como a capital cultural da Europa, a Constituição de Weimar já apresentava a famosa Cláusula 109, que determinou direitos iguais entre homens e mulheres (Eskildsen, 1995:3). No entanto, é

conclusões preliminares do grupo afirmam: "Our research collaboration examines how the Modern Girl emerged as a global phenomenon in the first half of the twentieth century. By wearing provocative fashions and pursuing romantic love, Modern Girls everywhere appeared to disregard the roles of dutiful daughter, wife and mother. We develop the Modern Girl as a heuristic category that allows new insights into forces of globalisation and manifestations of gendered modernity" (Barlow et alii, 2005:246). Em tradução livre, o trecho informa que "Nossa colaboração de pesquisa examina como a Modern Girl surgiu como um fenômeno global na primeira metade do século XX. Ao usar roupas provocativas e buscar o amor romântico, as Modern Girls em todos os lugares pareciam desconsiderar os papéis de filha, esposa e mãe obedientes. Desenvolvemos a Modern Girl como uma categoria heurística que permite novos conhecimentos sobre forças da globalização e manifestações de modernidade de gênero" . 
discutível até que ponto essa cláusula foi transportada para as ações cotidianas. Dorothy Rowe argumenta que qualquer sensação de aumento do poder das mulheres na ocasião não tem grande lastro no real, pois enquanto a presença das mulheres na força de trabalho - e portanto a realocação de seu papel econômico, ganhou força depois da Primeira Guerra Mundial sua presença concreta na esfera pública não sofreu nenhuma mudança drástica (Rowe, 1995:152). A dimensão econômica, no entanto, não pode ser ignorada, e Atina Grossnamm (apud Eskildsen, 1995:65) afirma que as milhares de jovens mulheres que entraram para o mercado de trabalho depois da Primeira Guerra Mundial causaram um grande impacto na percepção social de seus contemporâneos. Ela acrescenta ainda que o censo alemão de 1925 registrou a presença de um milhão e meio de mulheres que trabalhavam para se sustentar, o que significava mais de 35 por cento da força de trabalho total do país, e que, portanto,

a "Nova Mulher" não era um mero mito da imprensa ou uma ilusão paranóica de cientistas sociais, mas uma realidade que podía ser analisada e documentada (Grossnamm apud Eskildsen, 1995:65). ${ }^{3}$

Não por acaso, é precisamente na chave econômica que o acesso feminino à profissão da fotografia vai se dar. A fotografia era, nas primeiras décadas do século $\mathrm{XX}$, uma das poucas profissões socialmente aceitas para mulheres, à qual muitas recorreram, bem como uma das poucas possibilidades de continuidade dos estudos. As jovens na maioria das vezes deixavam suas cidades natais e viajavam para estudarem nos grandes centros, e haviam escolas de fotografia em Viena, Hamburgo, Dresden, Berlim e Paris (Csorba, 2009:12-15). No caso específico da Alemanha, já havia instituições educacionais voltadas para o ensino da técnica e da impressão fotográfica para

${ }^{3}$ No original: "the 'New Woman' was not at all a mere myth of the media or a paranoid delusion of some social scientists, instead it was social reality that could be analysed and documented". 
mulheres antes da virada do século XIX para o XX. É significativo, no entanto, que esse treinamento fosse voltado para o mercado para o trabalho em estúdio, especialmente o retrato, incluindo a feitura das cópias fotográficas e o trabalho no laboratório, além do retoque manual das imagens. A fotografia era ensinada para elas como um ofício, que era aberto a elas justamente porque na época ainda predominava a visão de que a fotografia não era arte. As academias de belas artes só foram admitir mulheres décadas depois. ${ }^{4}$

Também na Inglaterra, a fotografia em sua dimensão profissional era oferecida às jovens mulheres, como atesta um artigo no jornal The Times intitulado "Photography for girls!', em que era noticiado o início de um curso de fotografia na LCC Trade School for Girls, em Londres. O artigo afirmava que o curso era

\begin{abstract}
projetado para treinar garotas como assistentes para fotógrafos de retrato, cujas demandas a escola não conseguiu atender. A reitora espera que as meninas encontrem emprego em empresas de renome, e que as mais experientes e empreendedoras entre elas irão se tornar gerentes de estúdio ou abrir seus próprios estúdios (apud Ennis, 2005:24). ${ }^{5}$
\end{abstract}

Houve, desse modo, uma convergência de situações na Europa entre-guerras que possibilitaram a presença de mulheres no trabalho fotográfico. Ao mesmo tempo que a noção de mulher moderna ia abrindo espaço para as jovens mulheres buscarem maior independência a partir do trabalho, também uma educação

4 O ensino da fotografia para mulheres nesse momento enfatizava, por um lado, o seu aspecto de crafts, mas, por outro, também seu aspecto tecnológico, incluindo a técnica do então recém-descoberto raio x. Ver Eskildsen (1995:6364).

5 No original: "designed to train girls as assistants to portrait photographers, whose demands the school has been unable to meet. The head mistress expects that girls will find employment with firms of repute, and that the most expert and enterprising of them will ultimately become studio managers or will start studios of their own". 
mais liberal foi ofertada e, embora não contasse com o status de arte, permitia às filhas da classe média uma profissão que possibilitava em alguma medida a expressão criativa - muitas fotógrafas usavam o acesso aos laboratórios e o dinheiro ganho com o estúdio de retratos para fazer seu trabalho autoral e criativo. Por outro lado, especialmente na Europa continental do final da década de 1920 e na de 1930, as famílias de classe média foram perdendo a segurança financeira por conta da inflação, do antisemitismo, dos problemas sociais e políticos vividos no período. Assim, quando se fez necessário, essa geração de jovens treinadas em fotografia pôde também assumir a profissão, dessa vez para o próprio sustento. Isso tudo em um momento em que estava se consolidando a formação de uma indústria de comunicação de massas baseada na imagem.

Margaret Michaelis e Kati Horna fizeram parte dessa geração. Ambas estavam em Berlim entre 1930 e 1932, onde viveram em primeira mão o momento de amadurecimento tanto da mulher moderna quanto da imprensa ilustrada. As duas tiveram um treinamento formal em fotografia voltada para o retrato de estúdio.

Michaelis teve uma formação bastante completa. Ela estudou por cinco anos em Viena, de 1918 a 1921, no Instituto de Artes Gráficas e Pesquisas, que desde o final do século XIX era uma das principais instituições de ensino de fotografia na Áustria. Não surpreende que seu treinamento tenha sido feito com professores bastante conservadores e a partir de métodos tradicionais. Foi uma formação técnica, e imediatamente depois de terminada, Michaelis trabalhou em uma sequência de diferentes estúdios em Viena, Praga e, finalmente, Berlim a partir de 1929, onde por um curto período ela teve um estúdio próprio (Mendelson; Lahuerta, 1998:153-155).

Pelo que se tem notícia em seu arquivo e em sua biografia, foi em Berlim que Michaelis começou a ter um maior envolvimento com política, mais especificamente com o anarquismo do FAUD, no mesmo período em que começou a sua relação com Rudolf Michaelis, em 1929. A vinda de Kati Horna 
para Berlim no ano seguinte, por sua vez, não envolveu estudo em fotografia, mas sim prática política. Com apenas 18 anos, incentivada pelas ideias de Lajos Kassák, ela deixou a Hungria $e$ foi, segundo uma entrevista dada em 1962, "experimentar as realidades de ser uma operária" (Moorhead, 2010:59). Assim, embora seus pais tenham oferecido o dinheiro para que ela se matriculasse em um curso de secretariado, ela preferiu ir trabalhar em uma fábrica por meio período, e no tempo restante manteve atividades políticas ligadas à reivindicação de direitos trabalhistas - até que foi demitida por ter feito parte de uma manifestação de Primeiro de Maio.

A estada de Horna em Berlim acabou no mesmo período em que acabou a de Michaelis e quando tantas outras pessoas de ascendência judaica também deixaram o país - o ano de 1933, em que Hitler subiu ao poder. Tendo seu pai morrido durante sua ausência Horna voltou para Budapeste, e lá ingressou na escola de fotografia dirigida por Jószef Pécsi. A escolha pela carreira na fotografia, nesse momento, parece ter sido feita como um meio termo entre a insistência de sua mãe em que ela tivesse a formação apropriada para desenvolver um ofício e sua vontade de não se estabelecer definitivamente em seu país natal - já que, por ultrapassar as barreiras linguísticas e poder ser desenvolvida de forma autônoma, a fotografia era um dos poucos ofícios adequados à vida de imigrantes - além de ser ao mesmo tempo um meio que possibilitava a ela se sustentar e ter alguma atuação política ou social (Moorhead, 2010:59).

Em pouco tempo, ela e Michaelis estariam trabalhando como fotógrafas a serviço da revolução social espanhola e contra o fascismo. Estariam andando pelas ruas de Barcelona, viajando pelos territórios republicanos, empunhando suas câmeras exatamente como a jovem mulher de cabelo curto e roupa moderna fotografada por Michaelis (Imagem 1), que, de pé em cima do teto de um veículo estacionado, fotografa a multidão acompanhando o funeral do líder anarquista Buenaventura Durruti em Barcelona. No arquivo de Michaelis há outras tomadas desse evento, em que a multidão vista de cima ocupa todo o 
quadro. No entanto, nessa fotografia, ela se desviou um pouco da multidão, para incluir a presença no canto direito da neue Frau. Pelo ângulo em que foi tomada a fotografia, inferimos que Michaelis estava ela também em cima de um outro automóvel, além de voltada para a mesma cena que a outra jovem está fotografando. Essa imagem funciona, assim, como um comentário sobre o lugar da mulher moderna - que também é o de fotógrafa social. Ela é construída, pode-se argumentar, quase como um autorretrato.

Mulheres livres

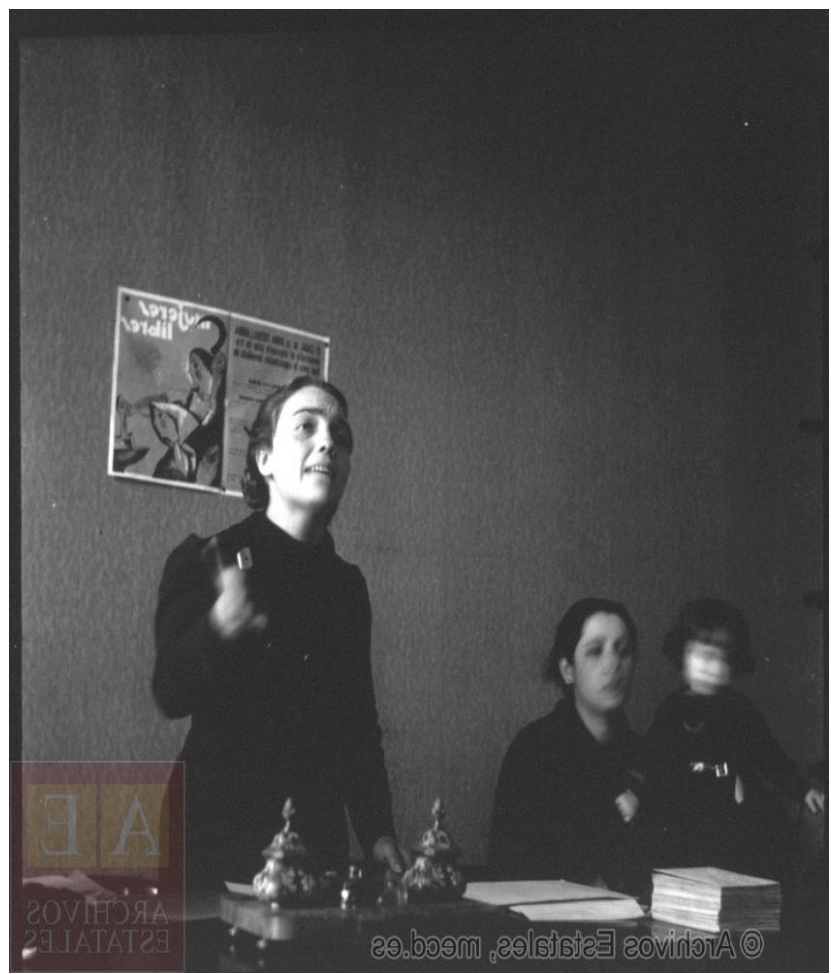

Imagem 2 - Kati Horna. Reunião na sede de Mujeres Libres, Espanha, 1937. Fonte: MECD. Centro Documental de la Memoria Histórica [http://pares.mcu.es/ParesBusquedas/servlets/Control_servlet]. 
Durante o conflito na Espanha, Horna e Michaelis não tiveram ação política direta nos sindicatos e partidos ou na frente de batalha, mas trabalharam na retaguarda junto à imprensa do lado republicano. Michaelis contribuiu com suas fotos para o Comissariat de Propaganda da Generalitat de Catalunya, entre outros trabalhos, e Horna trabalhou principalmente na revista anarquista Umbral, da qual foi redatora gráfica, mas também contribuiu para outras publicações anarquistas, como por exemplo Mujeres Libres. Nos documentos disponíveis e nas fotografias que sobreviveram, podemos encontrar alguns pontos de aproximação entre as fotografias $e$ as reportagens que Michaelis e Horna desenvolveram para o lado republicano, e, em sua maioria, tais aproximações têm relação com a questão do papel da mulher na revolução social e o anarco-feminismo.

Ambas retrataram Emma Goldman (1869-1940), grande representante do anarco-sindicalismo e defensora de longa data dos direitos das mulheres, de origem russa, mas tendo vivido entre a Europa e a América do Norte, sempre atuando em favor da causa libertária. Michaelis a retratou em sua primeira estada na Espanha em guerra, quando, em outubro de 1936, Goldman foi convidada a fazer uma viagem de carro pelo território de Aragão, controlado por anarquistas. Estavam com ela nessa viagem os jornalistas Hans-Erich Kaminsky, Anita Garfunkel, o anarquista e historiador Arthur Lehring, além de Margaret Michaelis, que foi na qualidade de fotógrafa da expedição (Ennis, 2005:155-157). A presença de jornalistas e de uma fotógrafa indicam que a viagem tinha também a intenção de ser divulgada como propaganda da revolução social. Da mesma forma, o retrato que Horna fez de Emma Goldman, em sua segunda estada na Espanha, em setembro de 1937, parece ter tido o propósito de acompanhar o artigo publicado na revista Umbral n ${ }^{\circ}$ 13, de 9 de outubro de 1937, em que é anunciado "Emma Goldman, veterana del anarquismo, nos visita" (Umbral, 1937:3), e na Tierra y Libertad $\mathrm{n}^{\circ} 40$, de 30 de outubro do mesmo ano. São dois retratos bastante diferentes, que denunciam de certo modo a mudança de ânimos quanto à situação do conflito nesse período de um ano. Enquanto no 
retrato de 1936, feito ao ar livre, Michaelis passa uma imagem altiva e forte de sua retratada, em 1937 Goldman já é retratada por Horna sentada, com uma expressão mais envelhecida.

Assim como Emma Goldman, a anarquista Etta Federn (1883-1951) foi uma mulher independente, militante feminista, que se dedicou à causa revolucionaria espanhola, e fez parte dos círculos tanto de Horna quanto de Michaelis durante o conflito. Ela nasceu em Viena, mas se mudou em 1905 para Berlim, onde fez parte da Federação de Mulheres Anarquistas (Syndikalistischer Frauenbund ou SFB) criada na Alemanha em 1921 pelo FAUD. Chegou em Barcelona em 1932 e sua casa logo se tornou um centro de encontro dos militantes do FAUD que emigraram para a Espanha; e Margaret e Rudolf Michaelis, que chegaram um ano depois, eram assíduos frequentadores. Em 1936, Federn passou a fazer parte do grupo Mujeres Libres, contribuindo, assim como Kati Horna, para a revista de mesmo nome.

No folheto intitulado "Como organizar una agrupación", editado pelo grupo Mujeres Livres cerca de 1936, e conservado no Centro Documental de la Memoria Histórica em Salamanca, são enumerados os objetivos do grupo, para serem divulgados entre as interessadas em se unirem ou montarem uma agrupação local do Mujeres Libres.

Se propone la Agrupación "MUJERES LIBRES":

$1^{\circ}$ Emancipar a la mujer de la triple esclavitud a que generalmente ha estado $y$ sigue estando sometida: esclavitud de ignorancia, esclavitud de mujer y esclavitud de productora.

$2^{\circ}$ Hacer de nuestra Organización una fuerza femenina consciente y responsable que actúe como vanguardia de la Revolución, y

$3^{\circ}$ Llegar a una auténtica coincidencia entre compañeros y compañeras; convivir, colaborar y no excluirse; sumar energías en la obra común.

Para el logro de todas estas finalidades crea Escuelas, Institutos, Bibliotecas; organiza conferencias, mítines, lecturas, etc.; todo cuanto, en fin, tienda a despertar el 
interés de las mujeres por las cuestiones sociales y el afán de una renovación de costumbres y un mejoramiento del medio ambiente (Mujeres Libres, c.1936:3-4).

Assim como esses objetivos centrais do grupo, os objetivos educacionais da revista Mujeres Libres também seguiam na direção de atrair a atenção das mulheres espanholas, em especial as trabalhadoras, para depois oferecer formação cultural e política que pudessem auxiliá-las na sua emancipação. ${ }^{6}$ Os artigos das primeiras três edições da revista, que foram publicadas no início de 1936, antes da sublevação militar, ficam nessa temática. Já os das edições seguintes, publicados durante o conflito civil (a revista e o grupo acabam com a derrota republicana, no início de 1939), incluem outros assuntos de caráter político e bélico. A trajetória da revista segue, de certo modo, os caminhos que o conflito - em princípio revolução e depois guerra civil - foi tomando.

Nos primeiros momentos em que estouraram os combates de rua, em julho de 1936, o lado republicano, levado pelo entusiasmo revolucionário tanto quanto pela carência de pessoal, apelou à mobilização de todos, incluindo as mulheres. Os anarquistas, assim como os demais partidários da República, incorporaram as mulheres em suas fileiras na frente de batalha as famosas milicianas, que aparecem sorridentes em cartazes $e$ fotografias da época, vestindo uniforme dos sindicatos e armas em mãos, as representantes espanholas da mulher moderna como descrita mais acima por Elizabeth Otto e Vanessa Rocco (2011).

6 Entre as iniciativas do grupo Mujeres Livres estão, nas palavras de Margareth Rago, "a criação de cursos de capacitação das operárias, nos quais desejavam 'despertar a consciência feminina para as ideias libertárias', como afirmavam; cursos de alfabetização e profissionalizantes, visando criar novas formas de inserção social para as mulheres pobres; centros de assistência médica e de educação sexual; creches; liberatórios de la prostitución, isto é, casas destinadas às que desejassem sair da prostituição e também 'para que as prostitutas pudessem ter tratamento médico e orientação para melhorar suas vidas', como afirmava Pura Perez, além de espaços, como os da revista que leva o nome do Grupo, em que puderam refletir sobre si mesmas e criar toda uma cultura feminista entre as militantes e simpatizantes do anarquismo" (Rago, 2005:138). 
No entanto, a ilusão de igualdade entre homens e mulheres na luta contra os rebeldes não sobreviveu por muito tempo, e já em setembro de 1936 são organizados os exércitos regulares da República, e a mulher é mandada de volta para a retaguarda (Greene, 1998:126, Pelizzon, 2011:139). A nova diretriz ficou clara no discurso da Passionaria, como é conhecida a importante militante comunista Dolores Ibarruri, que chamou "os homens ao combate, as mulheres ao trabalho", e, curiosamente, foi acatada pelos anarquistas, que normalmente não se submetiam às ordens governamentais e às do partido comunista (Ripa, 1996:5).

Durante as mudanças de diretrizes no lado republicano, é possível ver uma mudança de discurso nas páginas de Mujeres Libres, e a valorização do papel da mulher como mãe passou a ganhar bastante espaço. Esse seria agora o seu espaço, não mais a frente de batalha; e sua ação revolucionária consistiria então em gerar e cuidar dos "novos filhos da República" (Saornil, 1937:8-9). Ao mesmo tempo, o machismo presente dentro do próprio movimento anarquista, no qual os homens defendiam a revolução na rua, mas dentro de casa ainda reproduziam a subjugação de suas esposas e filhas, continuou a ser bastante denunciado. Emma Goldman, cujas contribuições apareciam frequentemente na revista, desde a primeira edição, publicou um artigo unindo esses dois aspectos aparentemente contraditórios da militância do grupo. "Situação social da mulher" apareceu na edição $n^{\circ} 6$ de Mujeres Libres, datada como Semana 21 da Revolução:

Mas, em geral, o homem, disposto sempre a lutar heroicamente por sua emancipação, está muito longe de pensar o mesmo em relação à do sexo oposto. (...) $\mathrm{Na}$ Espanha, por exemplo, a mulher é considerada muito inferior ao homem, como mero objeto de prazer $e$ produtora de filhos. Não me surpreenderia se somente os burgueses pensassem assim, porém, é incrível comprovar o mesmo conceito pré-diluviano entre os operários e até entre nossos próprios camaradas. (...) Mas o certo é que não pode existir uma verdadeira emancipação enquanto subsista o predomínio de um individuo sobre o outro, ou de 
uma classe sobre a outra. E muito menos realidade terá a emancipação da raça humana enquanto um sexo domine o outro. Além disso, a família humana integra ambos os sexos e a mulher é o mais importante dos dois, já que ela perpetua a espécie, e quanto mais perfeito for seu desenvolvimento moral e físico, mais perfeita será a raça humana (Goldman apud Rago; Biajoli, 2007:63-64).

Assim, apesar de o grupo reiteradamente defender que a mulher não havia "nascido para procriar", a revista publicou nos anos do conflito civil diversas manifestações da naturalidade do sentimento maternal na mulher. Uma das autoras de Mujeres Libres que tocava frequentemente nesse assunto é Etta Federn. $\mathrm{Na}$ coluna intitulada "Mujeres de las revoluciones", em que retratava por escrito diversas mulheres revolucionárias, Federn fez repetidas vezes referência aos "sentimentos maternais" delas, mesmo que não fossem mães (Ackelsberg, 1999:198). Mais do que outros assuntos, era reiterada na revista a temática da infância, numa tentativa de educar as mães a respeito, entre outras coisas, do parto, que deveria ser feito em hospitais e não em casa; do cuidado com os recém-nascidos, que deveriam ser alimentados com leite materno e não de origem animal; com a educação das crianças, que não deveriam sofrer castigos corporais e deveriam estar nas escolas laicas republicanas, etc.

Outro ponto em comum nos trabalhos de Kati Horna $e$ Margaret Michaelis durante o conflito na Espanha é justamente essa temática. A noção da mãe enquanto mulher revolucionária aparece de forma bastante explícita em uma reportagem fotográfica feita por Horna em diversos centros de acolhida de mulheres e maternidades republicanas, publicada na $U m b r a l n^{\circ} 12$, de setembro de 1937, e na Mujeres Libres no 11, de 1938, já discutida em outros lugares. ${ }^{7} \mathrm{Na}$ reportagem - cujo texto é de Lucia Sanchez Saornil, uma das fundadoras do grupo Mujeres Libres - também é ressaltada a assistência dada pelo governo republicano às mães e às crianças pequenas. Esse mesmo tema

7 Ver, em especial, Zerwes (2016).. 
aparece em um trabalho fotográfico de Michaelis publicado no folheto de propaganda catalão La Revolució I L'Assistència Social, publicado também em 1937.8

Parte significativa do arquivo que as duas fotógrafas salvaram guardando consigo durante fugas e imigrações é de imagens de cuidado com as crianças. Elas, na grande maioria das vezes, ressaltam o papel da ciência e das iniciativas laicas, seja por meio do ensino formal, seja no tratamento médico, como é o caso das Imagens 3 e 4 . Sem dúvida, são imagens de propaganda republicana. Pode-se argumentar que sejam também propaganda da atuação da anarquista Federica Montseny, a primeira ministra mulher da Espanha, que ocupou o Ministério da Saúde e Assistência Social do governo de Frente Popular de Largo Caballero a partir de finais de 1936. Montseny assumiu o ministério defendendo diversas reformas do atendimento médico e hospitalar, como a reorganização e a descentralização, além de reformas progressistas como a legalização do aborto e a criação das casas de acolhida para mulheres (Rago, 2005:134), como as retratadas na reportagem fotográfica de Horna e enfatizadas pelo texto de Saornil, para a Umbral mencionada anteriormente.

8 [http://www.cccb.org/xcentric/es/album-margaret_michaelis-16984]. 


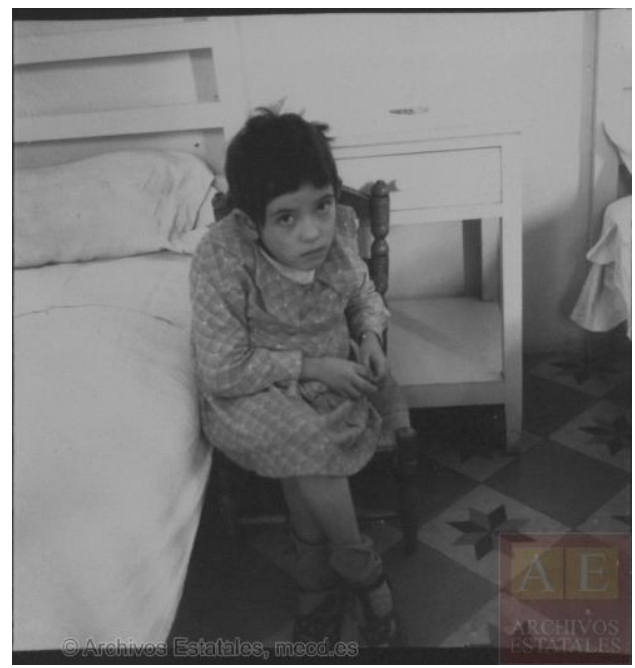

Imagem 3. Kati Horna. Sem título (Hospital del Pueblo). Barcelona, janeiro de 1937. Fonte: MECD. Centro Documental de la Memoria Histórica [http://pares.mcu.es/ParesBusquedas/servlets/Control_servlet].

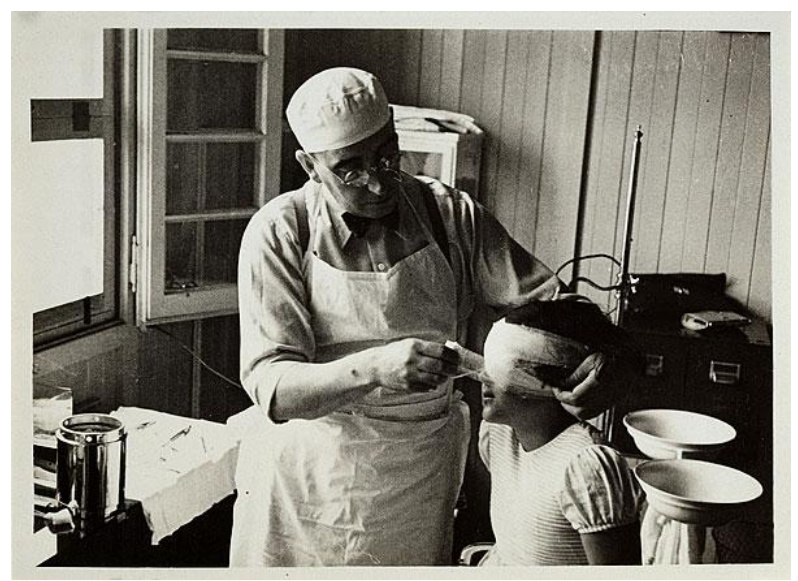

Imagem 4. Margaret Michaelis. Sem título (doutor com criança). Espanha, c. 1936. Fonte: National Gallery of Australia [http://cs.nga.gov.au/Detail.cfm?IRN=48725]. 


\section{Conclusão}

A ampla aceitação da figura mitificada da miliciana espanhola não resistiu por muito tempo. No entanto, quando as mulheres estavam sendo retiradas da frente de batalha, $e$ devolvidas para o âmbito privado, para desenvolver seu ativismo revolucionário dentro do papel de geradoras dos novos homens da República, as neue Frauen Margaret Michaelis e Kati Horna continuaram armadas com suas câmeras, como a jovem em cima do carro, fotografando em nome de sua militância da Imagem 1.

Antes de haver a mudança de diretrizes contra as mulheres no espaço público da guerra, a filósofa francesa Simone Weil foi uma das muitas mulheres voluntárias que foi para a frente de batalha. Em seus escritos, Weil demonstra ligações com a tradição libertária e o anarco-sindicalismo francês ao criticar qualquer manifestação de poder; constantemente reafirma a noção de luta de classes; e defende que o trabalho seja o elemento central da tanto da vida dos homens e mulheres, bem como sua possibilidade de emancipação (ver Buey, 2007:14-15). Já em sua vida e prática profissional, ela comprovou essa ligação optando por trabalhar como professora para operárias francesas. Ela chegou em Barcelona em setembro de 1936, poucas semanas depois do início do levante militar, ficando no país por cerca de dois meses. A experiência de Weil na Espanha foi marcada pela desilusão com os rumos que o conflito tomava, que, segundo sua visão, não eram os da Revolução, mas sim os da guerra. Cerca de 1938, ela escreveu:

En julio de 1936 yo estaba en París. No me gusta la guerra, pero lo que siempre me ha provocado más horror que la guerra es la situación de los que se encuentran en retaguardia. Cuando comprendí que, a pesar de mis esfuerzos, no podía dejar de participar moralmente en esta guerra, es decir, desear todos los días, a todas horas, la victoria de unos y la derrota de los otros, me dije que París era para mí la retaguardia, y tomé el tren para Barcelona con la intención de comprometerme. Era a principios de 
agosto de 1936. (...) Dejé España a mi pesar y con la intención de regresar; más tarde, voluntariamente no he hecho nada. No sentía ya ninguna necesidad interior de participar en una guerra que no era ya, como me había parecido al principio, una de campesinos hambrientos contra propietarios terratenientes y un clero cómplice de los propietarios, sino una guerra entre Rusia, Alemania e Italia. (Weil, 2007:523).

Essa reflexão de Weil sobre sua experiência é significativa para uma aproximação entre a vida e a obra de Michaelis e de Horna, bem como para a investigação histórica em seus arquivos, uma vez que ela remete ao que a documentação indica que tenham sido os motivos de Horna optar por ir para a Espanha - a Revolução - e o que a documentação dá indícios de que seja um dos motivos da fuga de Michaelis do país - a desvirtuação do movimento revolucionário anarquista pela crescente interferência soviética, e os perigos que essa interferência representava. ${ }^{9}$

Os trabalhos dessas duas fotógrafas permaneceram por décadas esquecidos. É, de certo modo, uma história de perdedores. Falando sobre o trabalho do grupo Mujeres Libres, que ficou igualmente soterrado durante os longos anos de ditadura franquista, Maria Clara Biajoli afirma que as experiências do grupo foram marginalizadas em pelo menos três âmbitos: por serem o lado perdedor da Guerra Civil e terem sido silenciadas

9 George Orwell, nas memórias que escreveu sobre o período em que lutou na guerra espanhola na milícia anarquista POUM, afirma que para Stalin não interessava que houvesse uma revolução proletária na Espanha e que, com a progressiva influencia soviética no governo espanhol, especialmente a partir de março de 1937, o governo republicano passou a reprimir os grupos mais radicais (Orwell, 2006:196-209). A dura perseguição ao POUM foi denominada de um dos "efeitos colaterais" da ajuda stalinista à República no livro de memórias de George Orwell. Seu líder, Andrés Nin foi assassinado pelos stalinistas em junho de 1937 (Orwell, 2006:146-222). Em março desse ano as notícias sobre prisões e perseguições de membros e simpatizantes de trotskistas e anarquistas já haviam chegado em Paris. Em abril, o assassinato de José Robles Pazos, ao que tudo indica pelos stalinistas, causou o rompimento entre Ernst Hemingway e John Dos Passos (Preston, 2009:62-92). 
durante a ditadura; por serem anarquistas, e assim terem sua Revolução subjugada aos interesses comunistas, cuja versão reescreveu o movimento revolucionário como guerra civil; e, por fim, por serem mulheres, tendo seu papel diminuído por uma história escrita por homens (Biajoli, 2007:20). O mesmo pode ser afirmado quanto às duas fotógrafas. Michaelis e Horna, como judias e anarquistas, sofreram sob os tempos sombrios da primeira metade do século XX. No entanto, elas puderam encontrar na fotografia um ofício que as permitiu ter os meios $e$ a independência para sua militância política, bem como para a imigração e a reconstrução de suas vidas em outros continentes.

\section{Referências bibliográficas}

ACKELSBERG, Martha A. Mujeres Libres. El anarquismo y lá lucha por lá emancipación de las mujeres. Barcelona, Virus, 1999.

ACKERS, L. Managing relationships in peripatetic careers: Scientific mobility in the european union. Women's Studies International Forum, 27, 2004, pp.189-201.

BARLOW, Tani et alii. The Modern Girl Around the World: A Research Agenda and Preliminary Findings. Gender and History, 17, $\mathrm{n}^{\circ}$ 2, Fall 2005, s/p.

BiAJOli, Maria Clara Pivato. Tempo de palavras: mujeres libres e a memoria da revolução espanhola. In: RAGO, Margareth; BIAJOLI, Maria Clara Pivato. Mujeres Libres da Espanha. Documentos da Revolução Espanhola. Rio de Janeiro, Achiamé, 2007.

BlANCO, Laura Sánchez; HuERTA, José Luis Hernández. La educación femenina en la revista Mujeres Libres. In: HERNÁNDEZ DíAZ, José María (ed). Prensa pedagógica y patrimonio histórico educativo. Contribuciones desde la Europa Mediterránea e Iberoamérica. Salamanca, Ediciones Universidad de Salamanca, 2013, pp.385-396.

BuEY, Francisco Fernández. Prólogo. In; WeIL, Simone. Escritos históricos y políticos. Madri, Editorial Trotta, 2007, pp.14-15. 
CsORBA, Csila. Picturing Progress: Hungarian Women Photographers 1900-1945. Women in the Arts Magazine, Washington, Spring 2009, pp.12-15.

ENNIS, Helen. Margaret Michaelis: Love, loss and photography. Canberra, National Gallery of Austrália, 2005.

ESKILDSEN, Ute. A chance to participate: A transitional time for women photographers. In: MESKIMMON, Marsha; WEST, Shearer. Visions of the Neue Frau. Aldershot / Brookfield, Scholar Press / Ashgate, 1995, pp.62-76.

GREENE, Patricia. Testimonio visual: iconografía femenina en los carteles de la Guerra Civil. Letras Peninsulares vol 11.1, spring, 1998, pp.119144.

MENDELSON, Jordana; LAHUERTA, Juan José. Margaret Michaelis. Fotografía, vanguardia y política en la Barcelona de la República. Valencia, IVAM Institut Valencià d'Art Modern, 1998.

MESKIMMON, Marsha; WeSt, Shearer. Visions of the Neue Frau. Aldershot / Brookfield, Scholar Press / Ashgate, 1995.

MoorHEAD, Joana. Kati Horna. In: MoorHEAD, Joana et. al. Surreal Friends. Leonora Carrington, Remedios Varo, Kati Horna. Surrey: Palant House Gallery, 2010, pp.54-69.

MUJERES Libres. Como organizar una agrupación. Ediciones Mujeres Libres, c.1936.

ORWELl, Geroge. Lutando na Espanha. São Paulo, Globo, 2006.

OTTO, Elizabeth; Rocco, Vanessa (eds). The New Woman International: Representations in Photography and Film from the 1870s through the 1960s. Ann Arbor, MI, University of Michigan Press, 2011. [http://quod.lib.umich.edu/d/dcbooks/9475509.0001.001/1:1/--newwoman-international-representations-in-

photography? $\mathrm{g}=$ dculture; $r \mathrm{rgn}=$ div $1 ; \mathrm{view}=\mathrm{toc} ; \mathrm{xc}=1-$ acesso em 20 maio 2016].

Pelizzon, Lisa. Más allá de la foto: La mirada de Kati Horna. Venezia, Tese (Doutorado em Studi Iberici i Anglo-Americani), Universitá Ca' Foscari, 2011. 
PRESTON, Paul. We Saw Spain Die. Foreign correspondents in the Spanish Civil War. Nova Iorque, Skyhorse Publishing, 2009.

RAGO, Margareth. Mujeres libres: anarco-feminismo e subjetividade na revolução espanhola. Verve, 7, 2005, pp.132-152.

RIPA, Yannick. Le genre dans l'anarcho-syndicalisme espagnol (19101939). Clio. Histoire, femmes et sociétés $\mathrm{n}^{\circ} 3,1996$ [clio.revues.org/470 - acesso em 20 maio 2016].

RodríGuez, José Antonio et. al. Kati Horna. México, DF; Barcelona: Editorial RM, 2013.

RowE, Dorothy. Desiring Berlin: Gender and modernity in Weimar Germany. In: MESKIMMON, Marsha; WeSt, Shearer. Visions of the Neue Frau. Aldershot / Brookfield, Scholar Press / Ashgate, 1995, pp.143-164.

SAORNIL, Lucia Sanchez. La maternidad bajo el signo de la revolución. Umbral no $12,2 / 10 / 37$.

WeIL, Simone. Escritos históricos y políticos. Prólogo de Francisco Fernández Buey. Madri, Editorial Trotta, 2007.

ZERWES, Erika. Tina Modotti e Kati Horna, fotógrafas produtoras de duas imagens situadas entre a fotografia obrera e o humanismo. História Unisinos, vol.20, 2016, pp.213-225. 